\title{
The Use of Unmanned Aerial Vehicles to Determine Differences in Vegetation Cover: A Tool for Monitoring Coastal Wetland Restoration Schemes
}

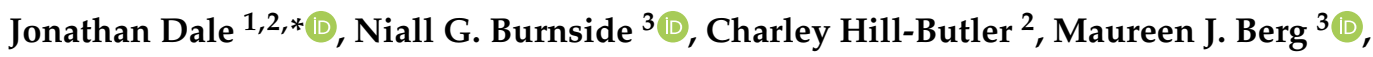 \\ Conor J. Strong ${ }^{3}$ and Heidi M. Burgess ${ }^{3}$ \\ 1 Centre for Agroecology, Water and Resilience (CAWR), Coventry University, Coventry CV8 3LG, UK \\ 2 School of Energy, Construction and Environment, Coventry University, Coventry CV1 5FB, UK; \\ ab1990@coventry.ac.uk \\ 3 Centre for Aquatic Environments, University of Brighton, Brighton BN2 4GJ, UK; \\ N.G.Burnside@brighton.ac.uk (N.G.B.); mb95@brighton.ac.uk (M.J.B.); C.Strong1@brighton.ac.uk (C.J.S.); \\ H.M.Burgess@brighton.ac.uk (H.M.B.) \\ * Correspondence: jonathan.dale@coventry.ac.uk
}

Received: 17 September 2020; Accepted: 4 December 2020; Published: 9 December 2020

check for updates

\begin{abstract}
Managed realignment (MR) sites are being implemented to compensate for the loss of natural saltmarsh habitat due to sea level rise and anthropogenic pressures. However, MR sites have been recognised to have lower morphological variability and coverage of saltmarsh vegetation than natural saltmarsh sites, which have been linked with the legacy of the historic (terrestrial) land use. This study assesses the relationship between the morphology and vegetation coverage in three separate zones, associated with the legacy of historic reclamation, of a non-engineered MR site. The site was selected due to the phased historical reclamation, and because no pre-breaching landscaping or engineering works were carried out prior to the more recent and contemporary breaching of the site. Four vegetation indices (Excess Green Index, Green Chromatic Coordinate, Green-Red Vegetation Index, and Visible Atmospherically Resistant Index) were calculated from unmanned aerial vehicle imagery; elevation, slope, and curvature surface models were calculated from a digital surface model (DSM) generated from the same imagery captured at the MR site. The imagery and DSM summarised the three zones present within the MR site and the adjacent external natural marsh, and were used to examine the site for areas of differing vegetation cover. Results indicated statistically significant differences between the vegetation indices across the three zones. Statistically significant differences in the vegetation indices were also found between the three zones and the external natural saltmarsh. However, it was only in the zone nearest the breach, and for three of the four indices, that a moderate to strong correlation was found between elevation and the vegetation indices $(r=0.53$ to 0.70$)$. This zone was also the lowest in elevation and exhibited the lowest average value for all indices. No relationship was found between the vegetation indices and either the slope or curvature in any of the zones. The approach outlined in this paper provides coastal managers with a relatively low-cost, low-field time method of assessing the areas of vegetation development in MR sites. Moreover, the findings indicate the potential importance of considering the historic morphological and sedimentological changes in the MR sites. By combining data on the areas of saltmarsh colonisation with a consideration of the site's morphological and reclamation history, the areas likely to support saltmarsh vegetation can be remotely identified in the design of larger engineered MR sites maximising the compensation for the loss of saltmarsh habitat elsewhere.
\end{abstract}

Keywords: managed realignment; unmanned aerial vehicle; coastal geomorphology; coastal wetlands 


\section{Introduction}

Coastal wetlands, such as saltmarshes and mudflats, provide a number of important ecosystem services including wave attenuation, habitats for juvenile fish species and water quality regulation [1]. However, there has been a global decline in the extent of these habitats $[1,2]$ as a result of urbanisation, land claim, changes in sediment supply, and erosion caused by sea level rise. To compensate for these losses, a number of schemes have been implemented [3], including managed realignment (MR); where coastal defences are not maintained or deliberately breached to allow tidal inundation of the previously defended terrestrial land which has often been reclaimed for agricultural purposes [4]. Despite the growing popularity of MR, the colonising saltmarshes within these sites have been recognised to be inequivalent ecologically and have substantial areas of bare ground in comparison to natural environments [5,6]. This has been associated with anoxic conditions as a result of poor drainage, caused by differences in the sediment sub-surface due the accretion of sediment over the terrestrial soil which had been disturbed, compacted, and altered by the previous agricultural activity [7,8]. In addition, it has been demonstrated that MR sites have lower topographic and morphological variability in comparison to natural environments [6,9], with terrestrial and agricultural morphological features such as tyre tracks and plough lines remaining visible several years after site breaching [10-12]. In natural marsh environments, where the typically shallow gradient controls morphological development, un-vegetated mudflat occupies the area below the elevation of neap high tide water level. Above this level, the marsh is colonised by halophytic vegetation and dissected by lower elevation morphological features such as dendritic creek networks and salt pans [13]. However, reduced topographic variability in MR sites may limit the range of elevation niches available to plant species and subsequently decrease saltmarsh diversity [14], with terrestrial morphological features reducing site drainage capabilities and contributing further to reduced topography and morphological heterogeneity.

Whilst historic morphological differences have been proposed as an explanation for the lower saltmarsh biodiversity and abundance found in MR sites, alterations to the sediment structure have been demonstrated to differ spatially across MR sites owing to variations in the former terrestrial land use [8]. Despite this, the spatial extent of the historic morphological influence on saltmarsh colonisation and coverage at a site-scale remains unknown. In recent years, unmanned aerial vehicles (UAVs) have become increasingly popular as a technique to measure large (site) scale morphological change in high resolution [15-17], facilitated by advancements in UAV technology, compatible sensors, and computer software $[18,19]$. Within coastal wetland environments, UAV technologies are becoming increasingly relevant for assessments of morphological variability [10,20] and ecological functioning [21,22], replacing lower resolution surveying techniques such as $\operatorname{LiDAR}[9,23,24]$. This study explores the potential to employ UAV technologies as a possible solution in order to assess saltmarsh coverage, and the relationship between vegetation cover and morphology, in MR sites. Specifically, we calculate four different vegetation indices derived from the red, green, and blue channels of the orthomosaic image obtained from the Cwm Ivy Marsh Managed Realignment Site, on the Gower Peninsular, Wales, on the northern coast of the Bristol Channel (Figure 1), in order to:

- Evaluate the potential of using simple vegetation indices, derived from UAV imagery, to characterise differences in vegetation coverage across the site in order to assess site development.

- Assess the relationship between site morphology and marsh vegetation coverage.

- Compare differences in coverage both inside and outside of the MR site. 


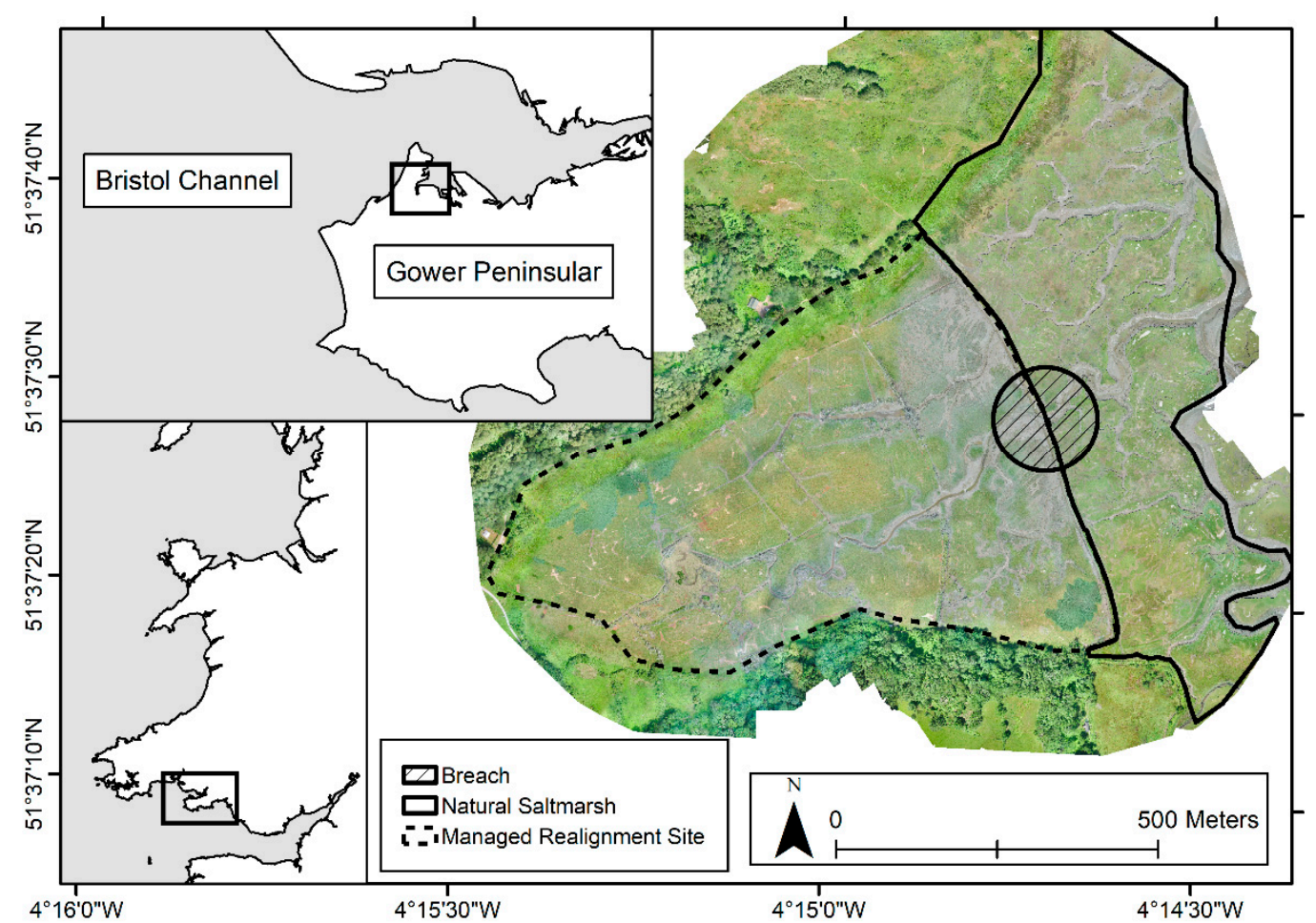

Figure 1. Orthophotography of the site from the unmanned aerial vehicle survey, and the regional and national setting (both inserts). The site outline is marked by the dashed black line, the external natural saltmarsh considered in this study indicated by the solid black line, and the creek drainage systems visible. The former sea wall is located at the boundary between the natural marsh and the managed realignment site, with the breach area identified.

\section{Materials and Methods}

\subsection{Study Site}

To encourage a range of intertidal habitats, the construction of MR sites often includes a mosaic of morphological features including channels, raised areas, and lowered sections. Whilst these features are designed to exploit the distinct elevational niches of different saltmarsh species, they may mask the influence that terrestrial features have on site evolution. Therefore, Cwm Ivy Marsh was selected for this study as this site is a non-engineered MR site and was not subjected to any landscaping prior to site breaching. The site, which had been drained gradually through a series of reclamations and used predominantly for grazing since medieval times (Corrinne Benbow, National Trust Site Manager, personal communication), is segregated into three zones (Figure 2) derived from pre-existing structures and morphological features associated with the reclamation history. The largest zone, Zone 1 , is located in the northwest of the site and consists of the secondary drainage channel and a number of straight artificial drainage ditches running perpendicular to the direction of flow. The boundary of Zone 1 is marked by a $10 \mathrm{~m}$ wide bank, bordered by ditches either side, which is likely to be a former embankment relating to historical reclamation. Zone 2 follows the main southern drainage channel through the site and is separated from Zone 3, which covers the entire eastern section of the MR site, by a small tree-lined earth embankment that can be detected visually (see Figure 3). This embankment is also likely to represent a previous, more recent, reclamation effort, which was then extended through the construction of the sea wall creating Zone 3. 


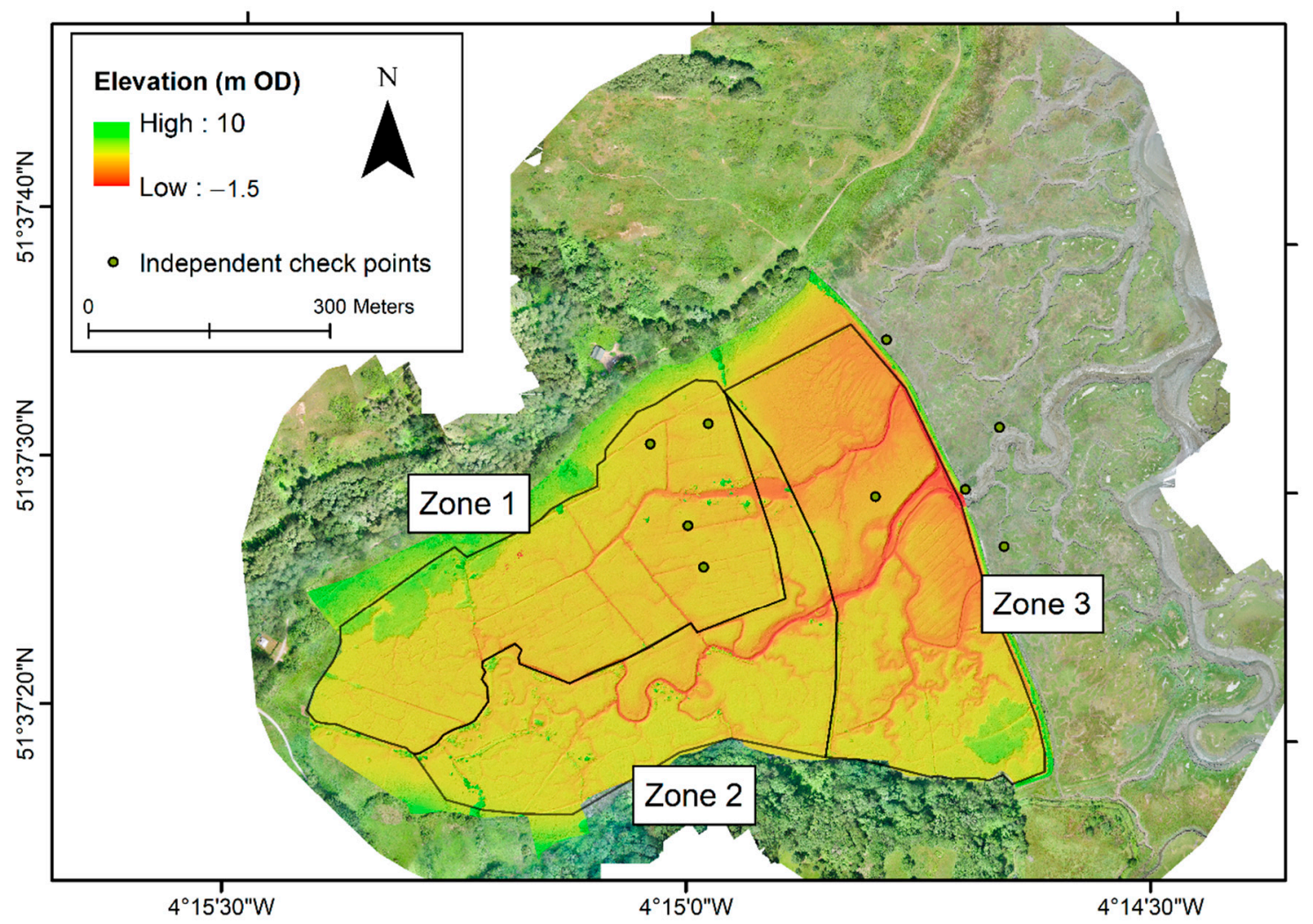

Figure 2. Site elevation (metres above Ordnance Datum (m OD)), the internal individual zones, and the independent model quality check points used in this study. Note that elevation outside the side was calculated and used to assess model quality, but has not been presented here.

Prior to breaching, the site was protected by a sea wall and drained into the surrounding natural marsh through a small sluice gate. In order to compensate for intertidal habitat loss elsewhere, and reduce the expenditure on unnecessarily maintaining flood defences of grazing land, Natural Resources Wales opted to stop maintenance of the seawall, which subsequently breached during a storm in August 2014. As a result, a macrotidal semi-diurnal intertidal system was formed behind the sea wall and the external natural marsh system. The area of the MR site is approximately $383,000 \mathrm{~m}^{2}$, and comprises saltmarsh vegetation including Salicornia, Puccinellia, and Suaeda species.

\subsection{UAV Image Acquisition}

The MR site and surrounding 292,000 $\mathrm{m}^{2}$ of natural saltmarsh were surveyed on 3 July 2019 using an eBee Plus Real-Time Kinematic (RTK) fixed-wing UAV with a Sensor Optimised for Drone Applications (SODA) RGB camera. Flight lines were completed on a grid pattern with an $80 \%$ lateral and longitudinal image overlap. Such large overlap values were selected to facilitate increased pixel matching and optimised orthomosaic production; analysis indicated an overlap of over $5+$ images for every pixel, and an average of 950 matched 2D key points between image pairs. Multiple flights were flown at $90 \mathrm{~m}$ altitude capturing a total of 1047 images with a pixel resolution of $0.022 \mathrm{~m}^{-1}$. For the purpose of model accuracy, six ground control points (GCPs) were recorded using a differential global positioning system (dGPS); positional measurements were taken of markers laid out prior to surveying by a Leica AS19 GNSS antenna, a Leica Viva GS10 GPS receiver, and a Leica CS15 controller. Raw GPS measurements were imported into Leica Geo Office (v8.3). Network Receiver Independent Exchange Format (RINEX) correction data were obtained from Leica Smart Net UK \& Ireland, and used for post-processing of eBee Plus flight data and to correct the raw GPS data. Leica Geo Office reported the positional quality $(\mathrm{XYZ}$ ) for all dGPS points as $<0.02 \mathrm{~m}$. In addition to the six GCPs, nine independent 
check points were collected using dGPS measurements of markers deployed prior to surveying to act as an assessment of model quality (see Figure 2 for the position of the check point markers). Table 1 summarises the UAV properties used in this study.

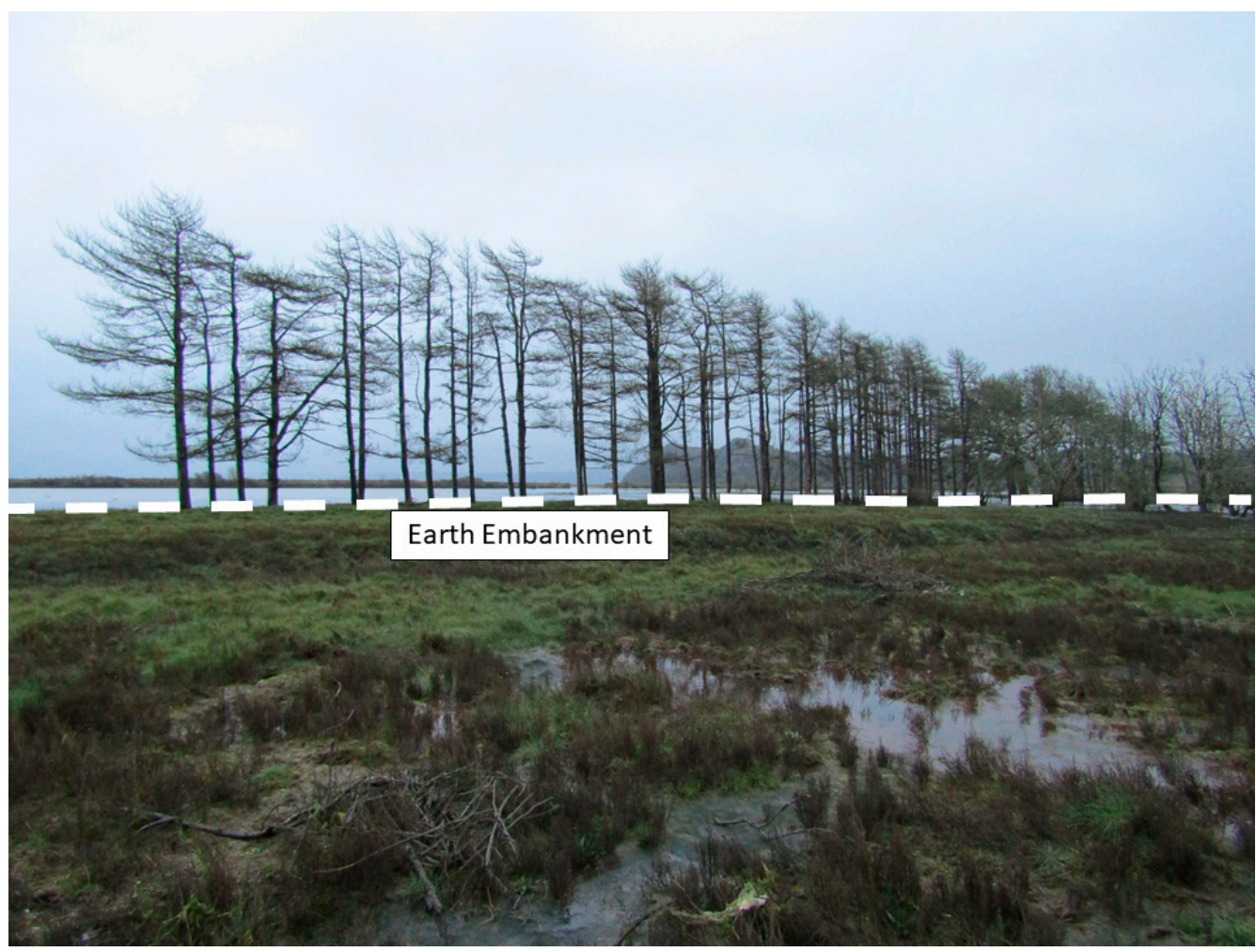

Figure 3. The tree-lined earth embankment which divides Zone 2 from Zone 3, marked by the white dashed line and labelled. The photograph was taken looking south-east towards the breach area across Zone 2 into Zone 3 (photography: H. Burgess).

Table 1. Images analysed, number of ground control points (GCPs), number of check points, resolution of the orthophotography and digital surface models (DSMs), reported error and calculated root-mean-square error (RMSE) between the DSMs, and check points for the unmanned aerial vehicles (UAV) survey.

\begin{tabular}{cc}
\hline UAV Property & Value \\
\hline Images Analysed & 1047 \\
No. of GCPs & 6 \\
No. of Check Points & 9 \\
Orthophotography Resolution (m/pix) & 0.022 \\
DSM Resolution (m/pix) & 0.022 \\
Reported X Error (m) & 0.001 \\
Reported Y Error (m) & $<0.001$ \\
Reported Z Error (m) & $<0.001$ \\
Calculated X RMSE (m) & 0.288 \\
Calculated Y RMSE (m) & 0.272 \\
Calculated Z RMSE (m) & 0.153 \\
\hline
\end{tabular}




\subsection{UAV Image Processing and Analysis}

Dense point clouds were produced from optimised camera locations using mild-depth filtering to ensure small and important details were preserved using Pix4D mapper (v4.2.27). From the resulting orthophotograph, the red, green, and blue channels were extracted and used to calculate four vegetation indices using tristimulus values. The tristimulus values provided a measure of light intensity based on the three primary colour values (blue (450-495 nm), green (495-570 nm), and red (620-750 nm)), and thus the visible spectrum. The four vegetation indices selected (Table 2) were: Excess Greenness Index (ExGI), Green Chromaticity Coordinates (GCC), Green Red Vegetation Index (GRVI), and Visible Atmospherically Resistant Index (VARI).

ExGI was calculated across the site and provided a difference measure between the green channel, and the red and blue channel. A range of studies have demonstrated the value of ExGI in classifying vegetation [25-27], and highlighted its ability to separate plants from bare soil. In addition, Larrinaga and Brotons (2019) indicated its potential to outperform other visible spectrum indices. GCC was also calculated across the site, and used to derive chromaticity coordinates as ratios calculated from one tristimulus value (Green) over the sum of all three tristimulus values (RGB). Previous studies have indicated that this index may be influenced less by differences in illumination and camera properties [25], and may better characterise plant responses to varied environmental conditions and plant phenology $[18,26]$. GRVI was calculated as it is considered to be advantageous as a plant phenological indicator due to its responsive nature to leaf senescence [28], and has become a popular method for determining ground cover including in coastal wetlands [22]. Finally, VARI was included in the analysis as it is suggested to improve upon GRVI, by its compensation for atmospheric effects [29]. Although UAV data would be expected to be influenced far less by atmospheric effects than satellite data due to the flight altitude, meaning a full atmospheric correction would typically be unnecessary, it was included within the analysis as there may be a potential local increase due to salt, aeolian sediments, and other airborne particulates.

Table 2. Vegetation indices selected in the present study. Vegetation indices were used to assess their potential to discern different morphological zones within the Cwm Ivy Marsh site.

\begin{tabular}{ccc}
\hline Vegetation Indices & Equation & Reference \\
\hline Excess Greenness Index (ExGI) & $E x G I=2 \times G-(R+B)$ & $\begin{array}{c}\text { Larrinaga and Brotons, 2019 [18]; } \\
\text { Sonnentag et al., 2012 [25]; } \\
\text { Woebbecke et al., 1995 [26]. }\end{array}$ \\
\hline Green Chromatic Coordinate (GCC) & $G C C=\frac{G}{R+G+B}$ & Sonnentag et al., 2012 [25]. \\
\hline $\begin{array}{c}\text { Green Red Vegetation Index (GRVI) } \\
\text { Visible Atmospherically Resistant } \\
\text { Index (VARI) }\end{array}$ & $G R V I=\frac{G-R}{G+R}$ & $\begin{array}{c}\text { Motohka et al., 2010 [28]; } \\
\text { Villoslada et al., 2020 [22]. }\end{array}$ \\
\hline \begin{tabular}{c} 
Ind \\
\hline
\end{tabular} & $V A R I=\frac{G-R}{G+R-B}$ & $\begin{array}{c}\text { Gitelson et al., 2002 [29]; Larrinaga } \\
\text { and Brotons, 2019 [18]. }\end{array}$ \\
\hline
\end{tabular}

These indices were selected over more complex representations of vegetation, such as the Normalised Difference Vegetation Index (NDVI), Enhanced Vegetation Indices (EVI), or Atmospherically Resistant Vegetation Index (ARVI) as these indices predominantly focus on chlorophyll, and are more sensitive to changes in vegetation type [30]. In addition, the indices selected for this study can all be derived using a standard RGB camera (which is typically available with any UAV) making this approach more affordable and easier to calculate for any site manager, stakeholder, or practitioner using open access photogrammetric software. 
Each index was calculated in ArcMap (v10.7) with all data aggregated using the Aggregate Tool, increasing the pixel resolution from 0.022 to $0.111 \mathrm{~m}^{-1}$ to account for individual pixels influenced by non-green features such as flowers. Prior to analysis, the vegetation indices were visually examined to identify any zones with differing vegetation cover within the MR site to assess spatial differences within the site. These differences were then confirmed statistically, via an ANOVA test conducted in Minitab (v19). An ANOVA test was also used to assess differences between each of the indices within each zone and to assess differences between each zone and the natural marsh. The morphology of the MR site was represented by the elevation (Figure 2), reconstructed using a Digital Surface Model (DSM) derived from Structure-from-Motion analysis [31]. From the resultant DSM, the slope and curvature were calculated, as a combination of both the profile (parallel to the slope and indicative of the direction of maximum slope) and planform (perpendicular to the direction of the maximum slope) curvatures using the Surface toolset in ArcMap's Spatial Analyst toolbox. Vegetation height was not removed from DSM as the majority of the marsh consisted of species of Salicornia, Puccinellia, and Suaeda, and therefore, the "canopy" height was within the error calculated for the elevation measurements. These three morphology descriptors were then compared to each vegetation index through Pearson's correlation analysis in Matlab R2020a.

\section{Results}

The four vegetation indices calculated are presented in Figure 4. Zone 1 had the highest in average elevation and average GCC, ExGI, and GRVI values (Figure 5; Table 3), whereas Zone 3 was the lowest in elevation and had the lowest average for all four greenness indices (Figure 5; Table 3) matching visual observations made in the field and visible in the orthophotography (Figure 1) of exposed mudflat and un-vegetated surfaces. The morphology of the southern section of Zone 3 consisted of a combination of more dendritic creek systems along, with a series of eleven parallel shallow ditches typically $10 \mathrm{~m}$ apart. These parallel ditches align with clay drainage pipes, installed at a depth of around $0.7 \mathrm{~m}$ in order to improve the agricultural potential of the reclaimed land [32]. However, following site breaching, the morphological signature of these features still remains, with the drains locally accelerating site drainage resulting in waterlogged furrows and drier ridges. Confirmation of the statistical difference between the zones was provided by ANOVA analysis, which indicated that all zones differed significantly (at the 99\% confidence level) from each other for all vegetation indices. Statistically significant differences were also found between the three zones and the natural marsh for all vegetation indices (also at the $99 \%$ confidence level).

In an assessment of the relationship between vegetation cover and morphology, a weak statistically significant $(p<0.01)$ positive correlation was found in Zone 1 between the four vegetation indices and elevation, with $\mathrm{r}$ values ranging between 0.35 and 0.44 (see Supplementary Information for full results). A similar strength relationship was found between ExGI and elevation in Zone $2(r=0.37$, $p<0.01$ ), although the strength of the relationship for the other indices was weaker in this zone with no relationship found between GCC and elevation. No relationship was also found between GCC and elevation in Zone 3; however, in this zone, a strong positive correlation was identified between ExGI and elevation $(r=0.70, p<0.01)$. Moderate statistically significant positive relationships were also identified for elevation against GRVI and VARI in Zone 3. ExGI, GRVI, and VARI were found to differ significantly to GCC in Zones 2 and 3, whereas in Zone 1, GRVI and VARI were significantly different to ExGI and GCC. In Zone 1, ExGI and GCC were also significantly different from each other (all at the $99 \%$ confidence interval). Neither the slope nor the curvature correlated with the three zones of the MR site. 

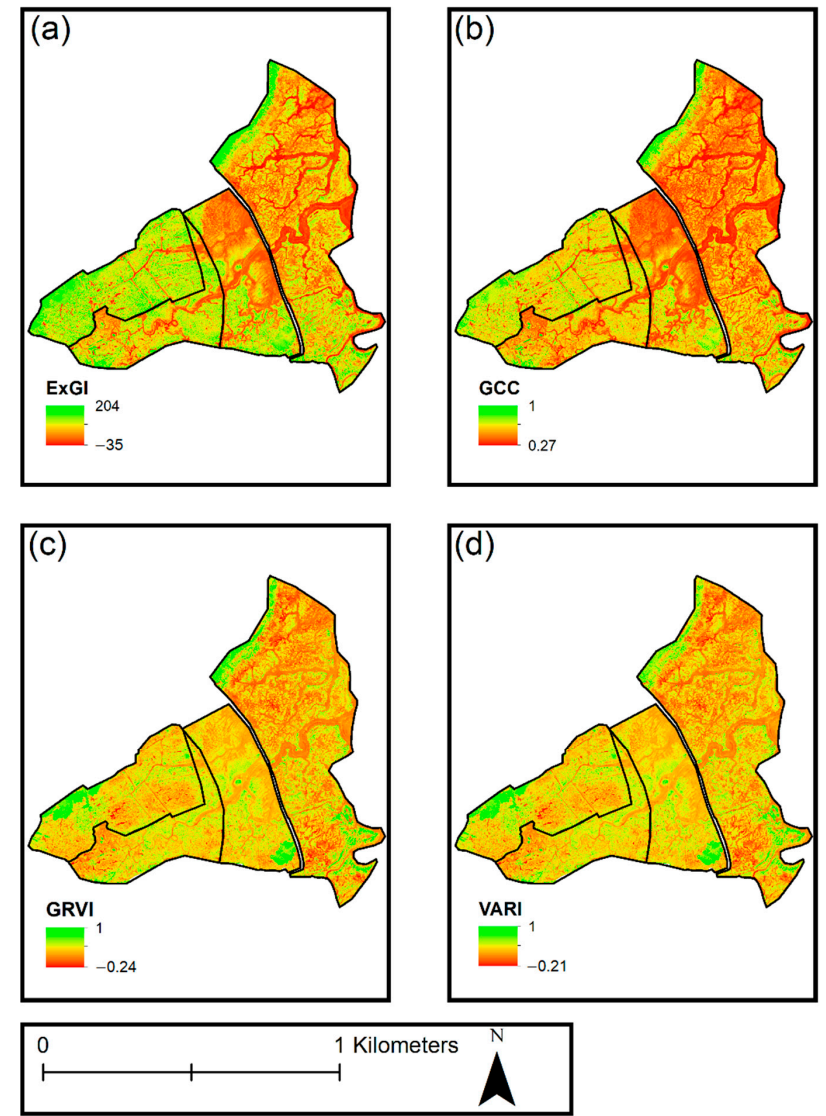

Figure 4. (a) Excess Green Index, (b) Green Chromatic Coordinate, (c) Green Red Vegetation Index, and (d) Visible Atmospherically Resistant Index calculated from the Cwm Ivy Marsh Managed Realignment Site.

(a)

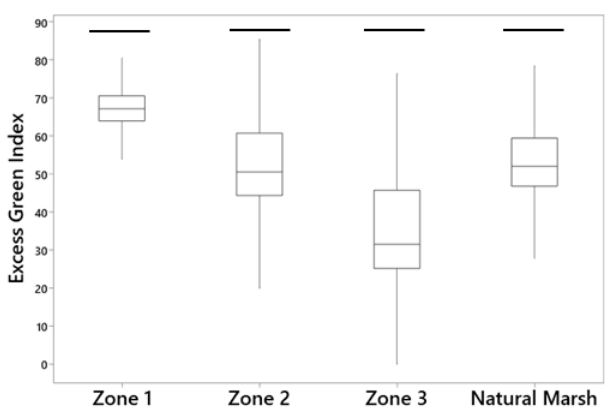

(c)

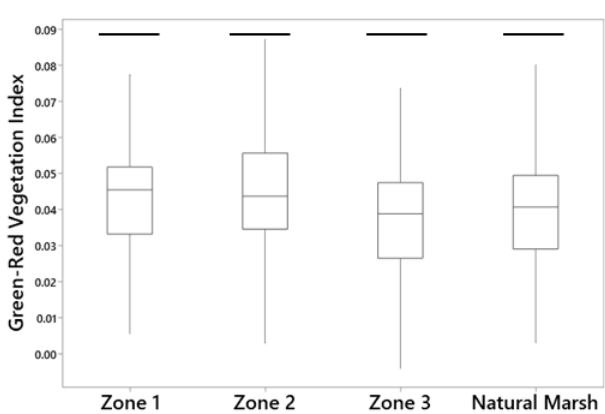

(b)

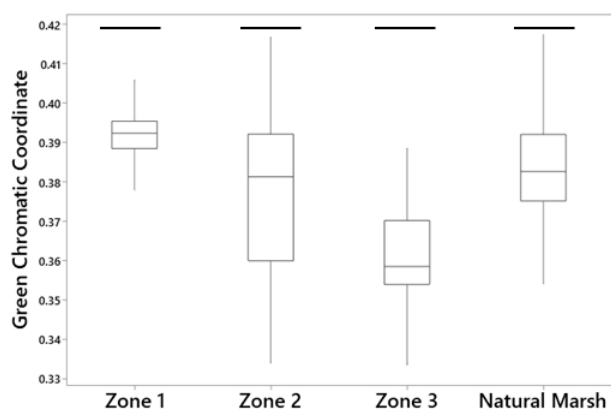

(d)

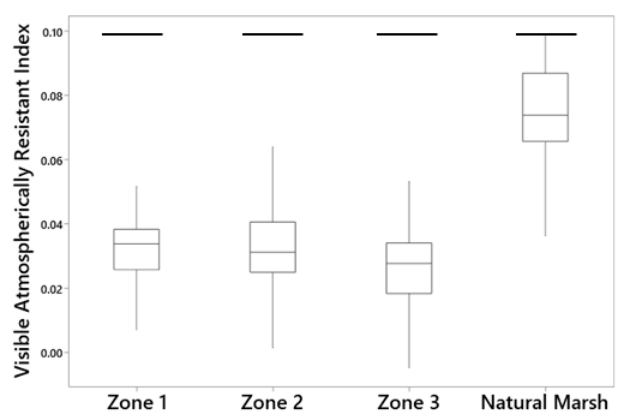

Figure 5. Distribution of vegetation indices for (a) Excess Green Index, (b) Green Chromatic Coordinate, (c) Green-Red Vegetation Index, and (d) Visible Atmospherically Resistant Index. All vegetation indices were significantly different $(p<0.01)$ in all zones. 
Table 3. Summary statistics of the size, elevation, and the Excess Greenness Index (ExGI), Green Chromaticity Coordinates (GCC), Green Red Vegetation Index (GRVI), and Visible Atmospherically Resistant Index (VARI) vegetation indices for the three zones identified within Cwm Ivy Marsh Managed Realignment Site (see Figure 1 for locations) and the surrounding natural marsh.

\begin{tabular}{|c|c|c|c|c|c|c|c|c|c|c|c|c|c|c|c|}
\hline & \multirow[t]{2}{*}{ Size $\left(m^{2}\right)$} & \multicolumn{2}{|c|}{$\begin{array}{l}\text { Elevation } \\
\text { (m OD) }\end{array}$} & \multicolumn{3}{|c|}{ ExGI } & \multicolumn{3}{|c|}{ GCC } & \multicolumn{3}{|c|}{ GRVI } & \multicolumn{3}{|c|}{ VARI } \\
\hline & & Mean & St. dev & Mean & St. dev & Max & Mean & St. dev & Max & Mean & St. dev & Max & Mean & St. dev & Max \\
\hline Zone 1 & 122,155 & 4.13 & 0.57 & 65.62 & 25.78 & 204 & 0.392 & 0.024 & 0.923 & 0.051 & 0.036 & 0.920 & 0.038 & 0.026 & 0.871 \\
\hline Zone 2 & 89,429 & 4.05 & 0.56 & 49.61 & 28.35 & 176 & 0.375 & 0.028 & 0.979 & 0.049 & 0.035 & 0.958 & 0.035 & 0.025 & 0.958 \\
\hline Zone 3 & 112,347 & 3.63 & 0.66 & 37.94 & 27.70 & 173 & 0.358 & 0.027 & 0.999 & 0.038 & 0.029 & 0.999 & 0.026 & 0.020 & 0.999 \\
\hline Natural Marsh & 292,189 & 3.72 & 1.01 & 54.88 & 34.52 & 217 & 0.377 & 0.036 & 0.999 & 0.047 & 0.038 & 0.999 & 0.073 & 0.057 & 0.999 \\
\hline
\end{tabular}




\section{Discussion}

\subsection{Vegetation Cover and the Influence of Site Morphology}

MR sites have been recognised to have lower topographic and morphological variability than equivalent natural saltmarsh environments, which have been associated with a relatively higher proportion of bare ground within the restored site [5,6,9]. To assess this relationship, four vegetation indices were calculated from UAV imagery taken at the Cwm Ivy Marsh Managed Realignment Site, and evaluated herein. Within the three zones of the MR site, recognised to relate to previous reclamations of the former saltmarsh environment, vegetation indices were typically higher within the most landwards and, therefore, probably the oldest zone, Zone 1 (Figure 5; Table 3). However, within this zone, only a weak relationship was found between the elevation and the vegetation indices. As Zone 1 is located at the back of the site, and is typically higher in elevation, it is possible that this zone is yet to be regularly exposed to intertidal inundation and saline conditions. If this is the case, this zone would not be expected to exhibit a typical intertidal saltmarsh profile $[33,34]$, with the vegetation indices not representing differences due to saltmarsh zonation or alternatively the morphology. However, no evaluation of the hydroperiod (the frequency and duration of inundation) or tidal prism [35] was possible here due to a lack of appropriate tidal data, in terms of the duration and distance of local measurements from the site, and consequently the influence of saltmarsh zonation has not been evaluated.

The strongest relationship between three of the four vegetation indices (ExGI, GRVI, and VARI) and elevation was found in Zone 3. This zone is located within the near breach area, and consequently is more exposed to currents, the macrotidal system, and probably increased exposure to saline conditions in comparison to the rest of the site. This zone was also lower, but more variable, in elevation than the rest of the site. As a result, it is likely that this area of the site is more developed and exhibiting a more typical intertidal marsh profile than the other two zones. Elevation is considered a key parameter in the design of MR sites [36], with the construction of many engineered sites including landscaping works through the redistribution, removal, or application of additional material in order to encourage a range of different habitat types [12,37-39]. Despite this, sites have been recognised to have large areas of bare ground [6], and these design works may still not result in the targeted range of species as they do not account for elevation changes caused by deposition of sediment post-site breaching [39]. These findings from Cwm Ivy Marsh, however, highlight the importance of also considering the pre-existing and historic morphology within the design of MR sites, and not pre-determining the location of different habitats through site engineering and landscaping [40,41]. The Cwm Ivy site was used predominantly for grazing, with no known history of intensive agricultural activity such as ploughing (Corrinne Benbow, National Trust Site Manager, personal communication), and therefore, may not have experienced the changes in sediment structure that have been associated with these processes [8,42]. Despite this, areas of differing vegetation cover still exist and appear to relate to former reclamation attempts. This legacy, if combined with a history of intensive agricultural activity, may further reduce the hydrological connectivity leading to poor drainage and anoxic conditions $[7,43]$ and inhibited saltmarsh colonisation.

\subsection{UAV Approaches as a Tool for Assessing Site Development}

Within the Cwm Ivy Marsh Managed Realignment Site, the three zones relating to the reclamation process all differed significantly from each other for the four vegetation indices (Figure 5). The use of the vegetation indices to identify these zones provides a new insight into the influence of historic land use changes at the site, in a similar approach to remote sensing and aerial photography analysis used in archaeological studies [42]. Whilst the use of these visible spectrum vegetation indices has been questioned in some previous studies due to the potential influence of camera setup and vegetation characteristics [43], variations in performance typically relate to factors associated with temporal studies such as rainfall or temperature [23]. As this study presents a direct comparison on contiguous 
sites, captured under consistent ambient conditions, the influence of these limitations is not expected to be as prominent.

The differences that were observed at Cwm Ivy Marsh are likely to result from changes to the sediment structure, which have been demonstrated in other studies to differ according to the terrestrial land use practice [18]. However, the duration for which a reclaimed site has been terrestrial may also have an effect, as this would allow more time for dewatering and desalinisation to occur, resulting in irreversible changes to the sediment structure $[14,40]$ which could lead to the establishment of non-vegetated areas following site breaching. This indicates the importance of understanding a site's long-term history beyond the type of agriculture, which has been the focus of previous studies into the influence the terrestrial legacy has on site development [8]. In turn, this understanding of a site's long-term history, and how the remaining signature of the historic terrestrial morphology may influence saltmarsh development, can be used to enhance the design of subsequent engineered MR sites. Analysis of this type may also be applied in order to assess areas within proposed MR sites that are less likely to readily support saltmarsh vegetation due to terrestrial morphological changes, although further analysis of this potential application is now required.

The approach outlined in this study provides a method for larger spatial-scale, higher resolution, low time, and labour-intensive analysis of the vegetation coverage, which can then inform the sampling location for assessments of species type, abundance, and diversity used in previous studies [15,44]. As a result, this approach is becoming increasingly appropriate for site wardens, coastal managers, practitioners, and stakeholders to monitor MR sites and to identify areas of targeted investigation following site breaching. Within this study, significant differences were found in Zone 1 between all variables except between GRVI and VARI, whereas only ExGI, GRVI, and VARI were significantly different to GCC in Zones 2 and 3. Given the similarity in the calculation of the GRVI and VARI indices [27], a similarity in the performance of these two indices would be expected. Furthermore, the similarities between ExGI, GRVI, and VARI in Zones 2 and 3, and the strength of the relationship with elevation within these zones, indicates that these indices outperform GCC in representing vegetation coverage as a result of morphological change in this instance. This is consistent with previous studies, which have recognised the effectiveness of these indices at discerning vegetation from soil due to the combination of the green and red channels [26], with green vegetation presenting: $\rho$ green $>\rho$ red, and soils presenting: $\rho$ green $<\rho$ red. Moreover, indices such as these are more sensitive to changes in green colour across the site.

It is, however, worth noting that ExGI modestly outperformed the other indices, most notable in Zones 2 and 3. Previous studies have demonstrated the value of ExGI in classifying vegetation [25-27], and highlighted the indices ability to separate plants from bare soil. The ExGI normalises the green channel (inflated by 2) against the sum of the red and blue channels, and thus the index has the potential to highlight chlorophyll reflectance values through characterisation of the green channel reflectance in vegetated versus non-vegetated areas of the site. Furthermore, and similar to the enhanced Normalised Difference Vegetation Index (eNDVI) [44], the normalisation of the green channel against the blue channel + red channel has the potential to amplify the recorded chlorophyll absorption values in vegetated areas when compared to non-vegetated areas. Some species, high in chlorophyll- $b$ content, have increased absorption of blue wavelength energy in this part of the electromagnetic spectrum. Equally, this distinction is not detected by indices solely, or predominantly, directed towards the red channel in isolation, or indices utilising sum total tristimulus reflectance values (e.g., $r+b+g$ ).

Further, more developed quantification of differences in vegetation dynamics, and different zones, within MR sites may be possible through the calculation of additional indices and following the collection of multispectral data such as near-infrared [45,46] and red-edge [9]. However, the currently available open access data of this nature (for example Landsat or Sentinel 2) are at a spatial resolution only appropriate for low resolution or regional level assessments [47,48]. Consequently, a UAV with multispectral sensors $[9,49]$ would be required to identify the important internal variability associated with different morphological features, increasing the cost and computation requirements and reducing 
the accessibility for site managers and industry stakeholders. In contrast, the method outlined in this study provides a genuine low-cost rapid assessment of vegetation coverage, the application of which will only increase through advances such as: further cost-reducing UAV technological developments, the ability to use images taken using commercially available cameras [50], and the availability of open access processing software. These developments, supported by baseline ground-truthing data, will then lead to an increased understanding of the post-breach development of MR sites, which can be used to maximise the design of future sites. Additionally, this technique may also be applied to other restoration and rewilding schemes, along with natural saltmarshes to assess differing, slower, or unusual recovery in response to morphological change and other modifications, including high magnitude events such as storms.

\subsection{Differences between Restored and Natural Marshes}

Previous studies have identified differences in the abundance and coverage of saltmarsh vegetation in MR sites compared to natural marshes [5,6]. Analysis of vegetation cover at Cwm Ivy Marsh presented here indicated significant differences between the four vegetation indices. However, the natural marsh had lower average values for three of these indices (ExGI, GCC, and GRVI) than Zone 1 at the back of the MR site, although it is possible that freshwater vegetation remains in this zone due to the higher elevation and distance from the breach area. In order to assess this, classification mapping through multispectral analysis would be required, which is not possible using the method outlined in this study. In addition, multispectral analysis may also mitigate the impact of any vegetation that is not green. For example, at Cwm Ivy Marsh, an abundance of flowering Aster tripolium was noted within the natural marsh whilst conducting the survey. Due to A. tripolium's large purple flowers and the high resolution of the orthophotography (even after aggregating the data), it is possible that the tristimulus values of a number of individual pixels are representative of these flowers. Following the calculation of the vegetation indices, the external natural marsh had typically higher values than Zones 2 and 3 for all indices except GRVI, which does not consider the blue channel, and has been used elsewhere to indicate plant senescence [28]. Given the seasonal timing and nature of this study, is unlikely that plant senescence has had a significant influence, but it remains possible that GRVI is not representative of the true vegetation coverage on the natural marsh due to the influence of the vegetation florescence and colour. Furthermore, as GRVI does not include the blue band in its calculation, it is unlikely to fully distinguish the vegetation from the sediment, given the high moisture content of saltmarsh sediments and the associated spectral reflectance [45].

A multispectral approach would also allow for analysis of the plant health [46] in comparison to the natural saltmarsh, which may provide a further insight into the influence of site morphology and site history on saltmarsh development in MR sites. However, this approach assumes that the natural marsh is "healthy" and "natural", and without the influence of anthropogenic factors, which not always be the case. For example, at Cwm Ivy Marsh, the external natural saltmarsh is subject to grazing from sheep and horses, with cattle also regularly being introduced to intertidal marshes elsewhere [47]. In addition, land purchased in order to create MR sites is often leased back to farmers for grazing and, in some cases, grazing has taken such priority in the design of MR schemes that the entire site has been planned around it. This includes the site at Steart, Somerset, UK, one of the largest MR sites in the UK, where a herringbone channel shape was implemented to allow cattle to retreat to higher ground during high water [40], limiting the natural hydrological and morphological functioning of the site. Although grazing has been demonstrated to increase diversity and abundance amongst invertebrate communities [48], these practices have a negative impact on saltmarsh vegetation $[49,50]$. As a result, assessments made between vegetation in natural and restored saltmarsh environments where either or both marshes are grazed may not reflect the true marsh development or the influence of the MR site's terrestrial history. 


\section{Conclusions}

This paper assesses the application of UAV technologies for a site-scale evaluation of vegetation coverage, via four vegetation indices, in relation to morphological variability at the Cwm Ivy Marsh Managed Realignment Site, Gower Peninsular, Wales, a non-engineered MR site which used to be grazing land prior to site breaching. Analysis of the vegetation indices supports the identification of three separate zones within the MR site, relating to the site's reclamation history. However, a strong relationship between the vegetation indices and morphology $(r=0.53$ to 0.70$)$ was only found between elevation and three of the indices (ExGI, GVRI, and VARI) in Zone 3, the zone with the lowest average value for all vegetation indices, but also the zone nearest the breach area and lowest in elevation, and therefore, likely to be the most advanced in terms of its transition from a terrestrial to intertidal environment. These results indicate that without the influence of a history of intensive agriculture, or site landscaping and engineering prior to breaching, differences in vegetation cover may still occur as a result of the historic terrestrial conditions, although elevation may provide some control in more exposed areas. Nonetheless, further work is required to confirm the influence of the morphology and sediment properties on differences in vegetation cover.

Differences were found between the internal restored and external natural saltmarsh coverage, although further multispectral analysis would now be required to assess differences in vegetation health and species classification mapping. However, analysis of this type is still applicable for coastal managers and site wardens as the approach offers a rapid relatively low-cost method of assessing differences in vegetation coverage in MR sites in order to inform future field-based surveys of vegetation abundance and diversity; findings from this study indicated that ExGI was the most appropriate index for representing vegetation cover, due to the indices ability to separate plants from bare soil. This approach can also be applied to consider the morphological signature that remains as a result of site history and legacy, including the reclamation processes and any differences in terrestrial lands, when designing sites in order to develop an understanding of the areas most likely to be able to support colonisation of saltmarsh vegetation. A greater understanding of the influence that the historic morphology has on site development can then be incorporated into the design of larger engineered MR sites, maximising the delivery of habitat restoration to compensate for saltmarsh losses elsewhere.

Supplementary Materials: The following are available online at http://www.mdpi.com/2072-4292/12/24/4022/s1, Table S1: Pearson's correlation between the Excess Greenness Index (ExGI), Green Chromaticity Coordinates (GCC), Green Red Vegetation Index (GRVI), and Visible Atmospherically Resistant Index (VARI) vegetation indices and morphological characteristics for the three zones within Cwm Ivy Marsh Managed Realignment Site

Author Contributions: Conceptualization, J.D.; methodology, J.D. and C.H.-B.; software, N.G.B. and C.J.S.; data curation, N.G.B. and C.J.S.; formal analysis, J.D.; writing-original draft preparation, J.D.; writing-review and editing, N.G.B., C.H.-B., and M.J.B.; project administration, H.M.B.; funding acquisition, J.D. and H.M.B. All authors have read and agreed to the published version of the manuscript.

Funding: This research was funded by Natural Resources Wales. The APC was funded by Centre for Agroecology, Water and Resilience (CAWR), Coventry University.

Acknowledgments: The authors would like to thank Corrinne Benbow (National Trust), James Moon (Natural Resources Wales), and Alan Kearsley-Evans (National Trust) for their support, guidance, and for providing accommodation during the field campaign.

Conflicts of Interest: The authors declare no conflict of interest.

\section{References}

1. Barbier:, E.B.; Hacker, S.D.; Kennedy, C.; Koch, E.W.; Stier, A.C.; Silliman, B.R. The value of estuarine and coastal ecosystem services. Ecol. Monogr. 2011, 81, 169-193. [CrossRef]

2. Adam, P. Saltmarshes in a time of change. Environ. Conserv. 2002, 29, 39-61. [CrossRef]

3. Callaway, J.C. The Challenge of Restoring Functioning Salt Marsh Ecosystem. J. Coast. Res. 2005, 24-36. Available online: http://www.jstor.org/stable/25736613 (accessed on 7 December 2020).

4. French, P.W. Managed realignment-The developing story of a comparatively new approach to soft engineering. Estuar. Coast. Shelf Sci. 2006, 67, 409-423. [CrossRef] 
5. Mossman, H.L.; Davy, A.J.; Grant, A. Does managed coastal realignment create saltmarshes with 'equivalent biological characteristics' to natural reference sites? J. Appl. Ecol. 2012, 49, 1446-1456. [CrossRef]

6. Brooks, K.L.; Mossman, H.L.; Chitty, J.L.; Grant, A. Limited Vegetation Development on a Created Salt Marsh Associated with Over-Consolidated Sediments and Lack of Topographic Heterogeneity. Estuaries Coasts 2015, 38, 325-336. [CrossRef]

7. Spencer, K.L.; Carr, S.J.; Diggens, L.M.; Tempest, J.A.; Morris, M.A.; Harvey, G.L. The impact of pre-restoration land-use and disturbance on sediment structure, hydrology and the sediment geochemical environment in restored saltmarshes. Sci. Total Environ. 2017, 587-588, 47-58. [CrossRef]

8. Dale, J.; Cundy, A.B.; Spencer, K.L.; Carr, S.J.; Croudace, I.W.; Burgess, H.M.; Nash, D.J. Sediment structure and physicochemical changes following tidal inundation at a large open coast managed realignment site. Sci. Total Environ. 2019, 660, 1419-1432. [CrossRef]

9. Lawrence, P.J.; Smith, G.R.; Sullivan, M.J.P.; Mossman, H.L. Restored saltmarshes lack the topographic diversity found in natural habitat. Ecol. Eng. 2018, 115, 58-66. [CrossRef]

10. Dale, J.; Burgess, H.M.; Burnside, N.G.; Kilkie, P.; Nash, D.J.; Cundy, A.B. The evolution of embryonic creek systems in a recently inundated large open coast managed realignment site. Anthr. Coasts 2018, 1, 16-33. [CrossRef]

11. Dale, J. The Evolution of the Sediment Regime in a Large Open Coast Managed Realignment Site: A Case Study of the Medmerry Managed Realignment Site. Ph.D. Thesis, University of Brighton, Brighton, UK, 2018.

12. Spencer, K.L.; Harvey, G.L. Understanding system disturbance and ecosystem services in restored saltmarshes: Integrating physical and biogeochemical processes. Estuar. Coast. Shelf Sci. 2012, 106, 23-32. [CrossRef]

13. Allen, J.R.L. Morphodynamics of Holocene salt marshes: A review sketch from the Atlantic and Southern North Sea coasts of Europe. Quat. Sci. Rev. 2000, 19, 1155-1231. [CrossRef]

14. Moffett, K.B.; Gorelick, S.M. Alternative stable states of tidal marsh vegetation patterns and channel complexity. Ecohydrology 2016, 9, 1639-1662. [CrossRef]

15. Strick, R.J.P.; Ashworth, P.J.; Sambrook Smith, G.H.; Nicholas, A.P.; Best, J.L.; Lane, S.N.; Parsons, D.R.; Simpson, C.J.; Unsworth, C.A.; Dale, J. Quantification of bedform dynamics and bedload sediment flux in sandy braided rivers from airborne and satellite imagery. Earth Surf. Process. Landf. 2019, 44, 953-972. [CrossRef]

16. Lane, S.N.; Westaway, R.M.; Hicks, D.M. Estimation of erosion and deposition volumes in a large, gravel-bed, braided river using synoptic remote sensing. Earth Surf. Process. Landf. 2003, 28, 249-271. [CrossRef]

17. Long, N.; Millescamps, B.; Guillot, B.; Pouget, F.; Bertin, X. Monitoring the Topography of a Dynamic Tidal Inlet Using UAV Imagery. Remote Sens. 2016, 8, 387. [CrossRef]

18. Larrinaga, A.R.; Brotons, L. Greenness Indices from a Low-Cost UAV Imagery as Tools for Monitoring Post-Fire Forest Recovery. Drones 2019, 3, 6. [CrossRef]

19. Fonstad, M.A.; Dietrich, J.T.; Courville, B.C.; Jensen, J.L.; Carbonneau, P.E. Topographic structure from motion: A new development in photogrammetric measurement. Earth Surf. Process. Landf. 2013, 38, 421-430. [CrossRef]

20. Dale, J.; Burnside, N.G.; Strong, C.J.; Burgess, H.M. The use of small-Unmanned Aerial Systems for high resolution analysis for intertidal wetland restoration schemes. Ecol. Eng. 2020, 143, 105695. [CrossRef]

21. Veettil, B.K.; Ward, R.D.; Lima, M.D.A.C.; Stankovic, M.; Hoai, P.N.; Quang, N.X. Opportunities for seagrass research derived from remote sensing: A review of current methods. Ecol. Indic. 2020, 117, 106560. [CrossRef]

22. Villoslada, M.; Bergamo, T.F.; Ward, R.D.; Burnside, N.G.; Joyce, C.B.; Bunce, R.G.H.; Sepp, K. Fine scale plant community assessment in coastal meadows using UAV based multispectral data. Ecol. Indic. 2020, 111, 105979. [CrossRef]

23. Ward, R.D.; Burnside, N.G.; Joyce, C.B.; Sepp, K. The use of medium point density LiDAR elevation data to determine plant community types in Baltic coastal wetlands. Ecol. Indic. 2013, 33, 96-104. [CrossRef]

24. Chirol, C.; Haigh, I.D.; Pontee, N.; Thompson, C.E.; Gallop, S.L. Parametrizing tidal creek morphology in mature saltmarshes using semi-automated extraction from lidar. Remote Sens. Environ. 2018, 209, 291-311. [CrossRef]

25. Sonnentag, O.; Hufkens, K.; Teshera-Sterne, C.; Young, A.M.; Friedl, M.; Braswell, B.H.; Milliman, T.; O'Keefe, J.; Richardson, A.D. Digital repeat photography for phenological research in forest ecosystems. Agric. For. Meteorol. 2012, 152, 159-177. [CrossRef] 
26. Woebbecke, D.M.; Meyer, G.E.; Von Bargen, K.; Mortensen, D.A. Color Indices for Weed Identification under Various Soil, Residue, and Lighting Conditions. Trans. ASAE 1995, 38, 259-269. [CrossRef]

27. Guijarro, M.; Pajares, G.; Riomoros, I.; Herrera, P.J.; Burgos-Artizzu, X.P.; Ribeiro, A. Automatic segmentation of relevant textures in agricultural images. Comput. Electron. Agric. 2011, 75, 75-83. [CrossRef]

28. Motohka, T.; Nasahara, K.N.; Oguma, H.; Tsuchida, S. Applicability of Green-Red Vegetation Index for Remote Sensing of Vegetation Phenology. Remote Sens. 2010, 2, 2369-2387. [CrossRef]

29. Gitelson, A.A.; Kaufman, Y.J.; Stark, R.; Rundquist, D. Novel algorithms for remote estimation of vegetation fraction. Remote Sens. Environ. 2002, 80, 76-87. [CrossRef]

30. Xue, J.; Su, B. Significant Remote Sensing Vegetation Indices: A Review of Developments and Applications. J. Sens. 2017, 2017, 1353691. [CrossRef]

31. Westoby, M.J.; Brasington, J.; Glasser, N.F.; Hambrey, M.J.; Reynolds, J.M. 'Structure-from-Motion' photogrammetry: A low-cost, effective tool for geoscience applications. Geomorphology 2012, 179, 300-314. [CrossRef]

32. Robinson, M.; Armstrong, A.C. The Extent of Agricultural Field Drainage in England and Wales, 1971-1980. Trans. Inst. Br. Geogr. 1988, 13, 19-28. [CrossRef]

33. Rodwell, J.S. (Ed.) British Plant Communities: Volume 5-Maritime Communities and Vegetation of Open Habitats; Cambridge University Press: Cambridge, UK, 2001.

34. Foster, N.M.; Hudson, M.D.; Bray, S.; Nicholls, R.J. Intertidal mudflat and saltmarsh conservation and sustainable use in the UK: A review. J. Environ. Manag. 2013, 126, 96-104. [CrossRef] [PubMed]

35. Krolik-Root, C.; Stansbury, D.L.; Burnside, N.G. Effective LiDAR-based modelling and visualisation of managed retreat scenarios for coastal planning: An example from the southern UK. Ocean Coast. Manag. 2015, 114, 164-174. [CrossRef]

36. Howe, A.J.; Rodriguez, J.F.; Spencer, J.; MacFarlane, G.R.; Saintilan, N. Response of estuarine wetlands to reinstatement of tidal flows. Mar. Freshw. Res. 2010, 61, 702-713. [CrossRef]

37. D’Alpaos, A.; Lanzoni, S.; Marani, M.; Bonornetto, A.; Cecconi, G.; Rinaldo, A. Spontaneous tidal network formation within a constructed salt marsh: Observations and morphodynamic modelling. Geomorphology 2007, 91, 186-197. [CrossRef]

38. Burgess, H.; Kilkie, P.; Callaway, T. Understanding the Physical Processes Occurring within a New Coastal Managed Realignment Site, Medmerry, Sussex, UK. In Coastal Management: Changing Coast, Changing Climate, Changing Minds; ICE Publishing: London, UK, 2016.

39. Dale, J.; Burgess, H.M.; Cundy, A.B. Sedimentation rhythms and hydrodynamics in two engineered environments in an open coast managed realignment site. Mar. Geol. 2017, 383, 120-131. [CrossRef]

40. Burgess, K.; Pontee, N.; Wilson, T.; Lee, S.C.; Cox, R. Steart coastal management project: Engineering challenges in a hyper-tidal environment. In From Sea to Shore-Meeting the Challenges of the Sea: (Coasts, Marine Structures and Breakwaters 2013); ICE Publishing: London, UK, 2013; pp. 665-674.

41. Pearce, J.; Khan, S.; Lewis, P. Medmerry Managed Realignment-Sustainable Coastal Management to Gain Multiple Benefits; ICE Publishing: London, UK, 2011.

42. Dent, D.L.; Downing, E.J.B.; Rogaar, H. Changes in structure of marsh soils following drainage and arable cultivation. J. Soil Sci. 1976, 27, 250-265. [CrossRef]

43. Tempest, J.A.; Harvey, G.L.; Spencer, K.L. Modified sediments and subsurface hydrology in natural and recreated salt marshes and implications for delivery of ecosystem services. Hydrol. Process. 2015, 29, 2346-2357. [CrossRef]

44. Strong, C.J.; Burnside, N.G.; Llewellyn, D. The potential of small-Unmanned Aircraft Systems for the rapid detection of threatened unimproved grassland communities using an Enhanced Normalized Difference Vegetation Index. PLoS ONE 2017, 12, e0186193. [CrossRef]

45. Huete, A.R. Remote sensing for environmental monitoring. In Environmental Monitoring and Characterization; Artiola, J.F., Pepper, I.L., Brusseau, M.L., Eds.; Academic Press: Burlington, MA, USA, 2004; pp. 183-206.

46. Mafi-Gholami, D.; Zenner, E.K.; Jaafari, A.; Ward, R.D. Modeling multi-decadal mangrove leaf area index in response to drought along the semi-arid southern coasts of Iran. Sci. Total Environ. 2019, 656, 1326-1336. [CrossRef]

47. Pagès, J.F.; Jenkins, S.R.; Bouma, T.J.; Sharps, E.; Skov, M.W. Opposing Indirect Effects of Domestic Herbivores on Saltmarsh Erosion. Ecosystems 2019, 22, 1055-1068. [CrossRef] 
48. Ford, H.; Garbutt, A.; Jones, L.; Jones, D.L. Grazing management in saltmarsh ecosystems drives invertebrate diversity, abundance and functional group structure. Insect Conserv. Divers. 2013, 6, 189-200. [CrossRef]

49. Kiehl, K.; Eischeid, I.; Gettner, S.; Walter, J. Impact of different sheep grazing intensities on salt marsh vegetation in northern Germany. J. Veg. Sci. 1996, 7, 99-106. [CrossRef]

50. Andresen, H.; Bakker, J.P.; Brongers, M.; Heydemann, B.; Irmler, U. Long-term changes of salt marsh communities by cattle grazing. Vegetatio 1990, 89, 137-148. [CrossRef]

Publisher's Note: MDPI stays neutral with regard to jurisdictional claims in published maps and institutional affiliations.

(C) 2020 by the authors. Licensee MDPI, Basel, Switzerland. This article is an open access article distributed under the terms and conditions of the Creative Commons Attribution (CC BY) license (http://creativecommons.org/licenses/by/4.0/). 